\title{
Macrostrat: a platform for geological data integration and deep-time Earth crust research
}

\author{
Shanan E. Peters, ${ }^{1,}$ a) Jon M. Husson, ${ }^{1,2}$ and John J. Czaplewski ${ }^{1}$ \\ ${ }^{1)}$ Department of Geoscience, University of Wisconsin-Madison, 1215 W. Dayton Street, Madison, WI 53706, \\ USA. \\ ${ }^{2)}$ School of Earth and Ocean Sciences, University of Victoria, Victoria, BC V8W 2Y2, \\ Canada.
}

(Dated: 26 January 2018)

Characterizing the lithology, age, and physical-chemical properties of rocks and sediments in the Earth's upper crust is necessary to fully assess energy, water, and mineral resources and to address many fundamental questions in the Earth sciences. Although a large number of geological maps, regional geological syntheses, and sample-based measurements have been produced, there is no openly available database that integrates rock record-derived data while facilitating large-scale, quantitative characterization of the volume, age, and material properties of the upper crust. Here we describe Macrostrat, a relational geospatial database and supporting cyberinfrastructure that is designed to enable quantitative spatial and geochronological analyses of the entire assemblage of surface and subsurface sedimentary, igneous and metamorphic rocks. Macrostrat now contains general, comprehensive summaries of the age and properties of 33,903 lithologically and chronologically-defined geological units distributed across 1,474 regions in North and South America, the Caribbean, New Zealand, and the deep sea. Sample-derived data, including fossil occurrences in the Paleobiology Database, more than 180,000 geochemical and outcrop-derived measurements, and more than 2.1 million bedrock geologic map units from over 170 map sources, are linked to specific Macrostrat units and/or lithologies. Macrostrat has generated numerous quantitative results and its data infrastructure is being used in several independently developed mobile applications. However, it is necessary to expand geographic coverage and to refine age models and material properties to arrive at a more precise characterization of the upper crust globally.

Keywords: geological synthesis, Earth system science, relational databases, Application Programming Interface

\section{INTRODUCTION}

Alexander Ronov ${ }^{1}$ was one of the first geoscientists to demonstrate the scientific value of compiling spatially and temporally comprehensive data on the age, lithology, and volume of rocks in the upper continental crust. Using a combination of geological maps and borehole observations, Ronov and his team generated global rock volume estimates for general lithology types across geological epochs (or longer duration time intervals) in the Phanerozoic and latest Precambrian. In addition to providing basic data with which to describe large-scale changes in the rock record, Ronov's rock volume compilation served as the primary basis for calibrating Phanerozoic burial and weathering fluxes of biogeochemically important elements ${ }^{2}$ and for estimating a wide range of quantities, ranging from groundwater volumes ${ }^{3,4}$ to rock cycling rates $^{5-8}$.

Although Ronov's work was a scientific success and played a key role in the development of some of the first models describing the geochemical evolution of Earth's surface environment ${ }^{9,10}$, his initial compilations were inherently low resolution. The reason stems from the pioneering nature of the work, most of which was carried out in the 1960s and 1970s, and by his team's depen-

a) Electronic mail: peters@geology.wisc.edu dence on small-scale geologic maps and limited borehole data. Both sources of information focus less on geochronology and more on contact relationships and the spatial extent of general bedrock types. However, whatever Ronov's compilation may have lacked in temporal and lithological acuity was, in many ways, compensated for by the fact that it was globally comprehensive. The subsequent emergence of geochemical approaches to deciphering changes in Earth systems (e.g., ref. 11) shifted emphasis away from Ronov's laborious approach of compiling data on the rock record and towards the production of new geochemical proxy records, some of which could be extracted with more efficiency and with much higher temporal resolution in one or more well correlated stratigraphic sections. Nevertheless, many of the models used to interpret geochemical proxy records require that assumptions be made about burial and weathering fluxes, assumptions that are difficult to assess without independent data on the rock record ${ }^{12-16}$. When interrogating Earth history, there thus remains a great need for spatially and temporally complete quantitative descriptions of the rock record that can be combined with geochemical models. Data on the rock record are also critical to calibrating physical models of the upper crust, for modeling ground water volume (e.g., ref. 17), fluid flow (e.g., ref. 18, and geophysical anisotropy (e.g., ref. 19), and independently assessing the nature of geological sampling of fossils ${ }^{20-23}$ and other records.

There are several approaches that could be taken to 
arrive at a comprehensive space-time description of the upper crust that is useful for both scientific questions and for data integration and informatics initiatives. One end-member approach aims for the highest-possible resolution and uses only vetted, authoritative primary field data. This methodology is most useful when constructing databases that are targeted for specific measurement types, when effort is focused on small geographic regions, or when it is necessary to maximize precision and accuracy in order to address specific questions that depend on individual observations (e.g., the oldest fossil of a given animal clade, ref. 24). However, restricting data to that which is only considered today to be the most up-to-date and/or best available is impractical when characterizing the entire rock record on a continental or global scale. By definition, the best and highest resolution data are sparse relative to the full extent of the upper crust. An alternative approach is, therefore, to start with basic geological summaries that are spatially and temporally complete, but that may lack the highest possible resolution. Such comparatively simple geological summaries are ultimately based on primary field data and observations, but primary data are not the focus. An example is a geologic map, which represents field data and observations that have been transformed (using widely accepted protocols) into a comprehensive predictive model of surface and subsurface geology (see below).

Macrostrat's initial primary objective is to aggregate and systematize basic field-derived data products, such as geological maps and regional geologic columns, in order to synthesize a large number of primary field observations and measurements into a spatially and temporally complete description of the upper crust. There are several reasons why this starting point is useful, both scientifically and from an informatics perspective. For example, low-resolution, but also temporally and spatially complete descriptions of the basic space-time attributes of the rock record are a useful basis for estimating rock quantities and ages (sensu Ronov) and for assessing the stratigraphic distribution of proxy data, such as the stratigraphic completeness of paleontological sampling ${ }^{25}$. In addition, general but complete summaries of the upper crust can be used to link diverse rock record-derived geological datasets and to constrain the ages of their constituent data, in both a relative and absolute sense.

A case-in-point is the Paleobiology Database (PBDB: https://paleobiodb.org), which consists of geographically located and taxonomically identified occurrences of fossils extracted from the rock record in order to test, among other things, hypotheses about the trajectory of long-term biological diversity ${ }^{26-28}$. The ages of fossil occurrences in the PBDB are currently manually assigned to a chronostratigraphic age bin or bins at the time of data entry, but the geochronological time intervals assigned to collections are typically coarser than the stratigraphic rock units that yielded the fossils. Using the PBDB $\mathrm{API}^{29}$, it is possible to integrate PBDB fossil occurrences back into a database describing the rock record, thereby providing a mechanism to improve and update the temporal resolution of PBDB fossil occurrences automatically. Incorporating fossil collections into a comprehensive geological framework also establishes a mecha- nism by which other records extracted from rocks can be linked directly to fossil collections, such as radioisotopic age estimates.

From an informatics point of view, the most valuable aspect of structured databases, like Macrostrat, is that they contain lists of terms and known relationships between them (e.g., the Waldron Formation occurs in Indiana and it is Silurian in age). These types of known relationships can be leveraged during machine reading and learning tasks to help identify entities and improve the quality of machine-driven geological data extraction and inference tasks ${ }^{30,31}$.

Here, we describe the motivation for Macrostrat and its general data model. We then outline the cyberinfrastructure that currently supports the database and describe how that infrastructure can be accessed by software via an Application Programming Interface (API). The API currently supplies data to several third-party applications that are designed to support field work, data analysis, and educational and outreach activities. One such application is outlined as a working example of how new observations can benefit from and improve Macrostrat data. Finally, we present an overview of the data currently in Macrostrat and provide some basic results. These results demonstrate Macrostrat's scientific utility, while at the same time exposing the need for enhancing existing data by further refining spatial, temporal, and lithological resolution, and extending geographic coverage globally.

\section{THE MACROSTRAT DATA MODEL}

Macrostrat is a relational geospatial database currently deployed on unix-based systems in both a MariaDB and PostGIS-enabled PostgreSQL environment. The database is designed primarily to facilitate quantitative macrostratigraphic analysis of the entire upper crust. Macrostratigraphy, the analytical approach, is inherently chronostratigraphic in nature ${ }^{32}$. The basic unit of analysis in macrostratigraphy is, therefore, a temporal gapbound package of rock identified at a single geographic location ${ }^{33,34}$. A rock package can consist of any lithology, but the gaps that define the boundaries between packages depend on the operational definition of a gap. For example, if a gap is defined as a break in temporal continuity (e.g., a hiatus in sedimentation), then it is necessary to specify a duration threshold for gap recognition (e.g., 1 Myr). A gap duration threshold renders the continuum of temporal continuity that is inherent in the rock record into a binary distribution (presence and absence of rock of a given age at a given location). Alternatively, a gap could be defined by lithological attributes (e.g., a temporal gap in siliciclastic sediments could be occupied by a hiatus in deposition or by a shift to carbonate sediments). The analytical approach of macrostratigraphy is scale independent, and the ideal dataset would be compiled at the finest possible spatial, temporal and lithological resolution so as to allow the application of any arbitrary gap recognition criteria and scale of analysis (e.g., ref. 35). The strength of the current version of the Macrostrat 


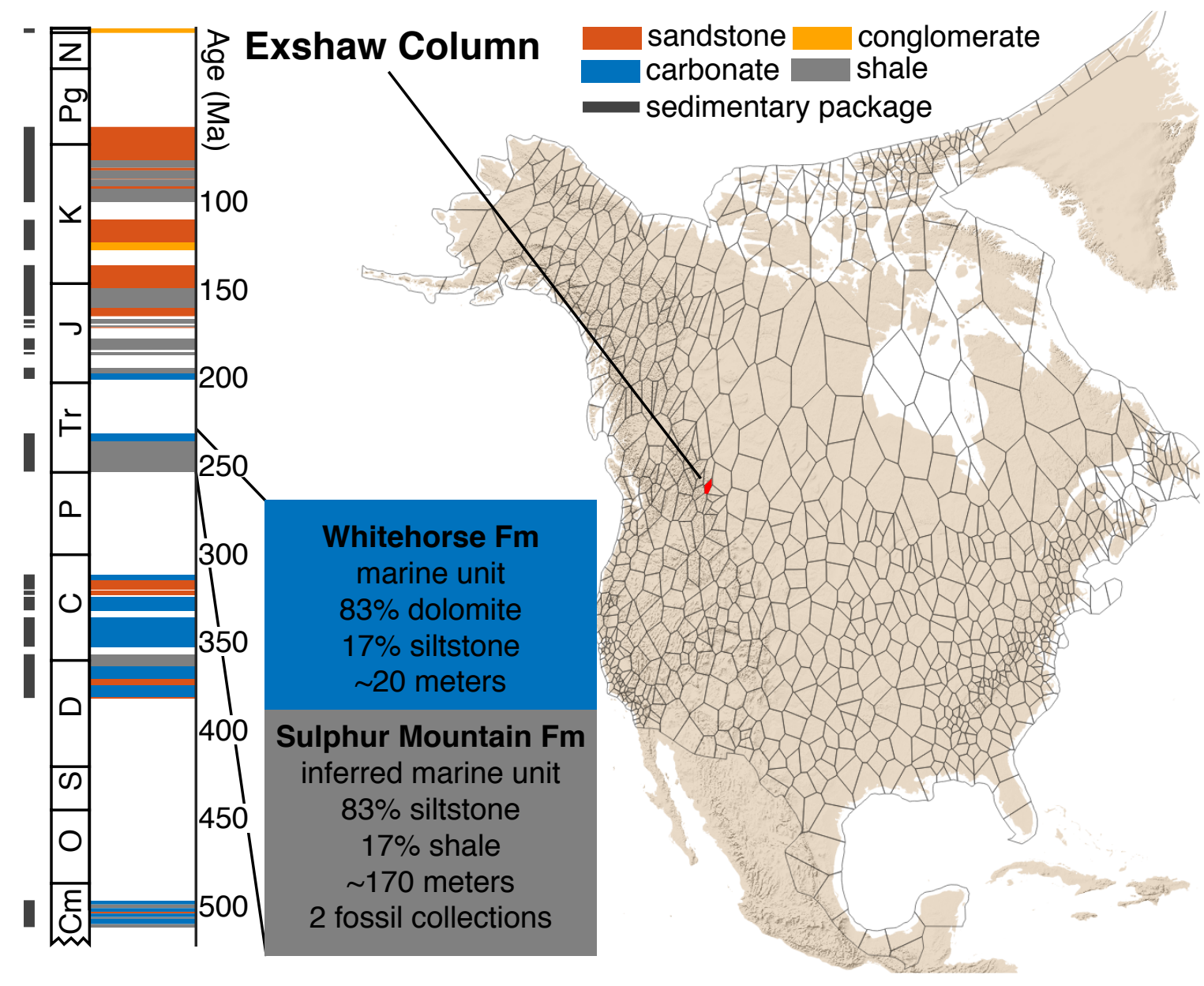

FIG. 1. Macrostrat North America, with an example column (titled "Exshaw") highlighted in red on the map and and rendered chronostratigraphically in the column on the left. Each unit is colored by its dominant lithology and grouped into packages on the basis of temporal continuity (indicated by the solid dark bars left of the geologic time scale). Although only the dominant lithology is represented by the colors of units, many units include multiple lithologies and estimates for the relative volumetric abundance of each (e.g., the expanded Triassic units identified as the Whitehorse Formation and the Sulphur Mountain Formation consist primarily, but not exclusively, of dolomite and siltstone, respectively).

dataset is its ability to characterize spatial and temporal variation in the upper crust that occurs on the scale of a geological province, basin, or continent.

Although the quantitative framework defined by macrostratigraphy is a good descriptor of the core organizational concept that motivated database development, the structure of the database is organized around a more basic component and includes several additional features, which are outlined below.

\section{A. Macrostrat Units}

The fundamental object in the Macrostrat database is called a "unit," which represents a body of rock or sediment that is recognized at the time of data compilation as being genetically, lithologically and/or chronologically distinct from other such adjacent units in a single geographic location or region. A Macrostrat unit could, therefore, consist of a thickness of sediment identified in a measured section or core (e.g., a bed), or a Macrostrat unit could consist of a lithostratigraphic formation or other rock body that is described as physically and temporally distinct in a regionally composited geological record (e.g., a geological map unit or a lithostratigraphic unit in a regional stratigraphic column). In all cases, Macrostrat units are recognized within a single geographic region, referred to as a "column". Each Macrostrat "column" consists of a geospatial polygon defining the lateral boundaries of the focal region (often interpolated), along with descriptive metadata for that region, such as references supplying column data, column name etc. (Fig. 1).

Units in Macrostrat are described by a variety of physical attributes, including thicknesses (usually expressed as a maximum and a minimum within the focal region), dominant and subordinate lithologies, attributes that modify lithologies, inferred environments of deposition/emplacement, and stratigraphic nomenclature (Fig. 1). All of the attributes that can be assigned to Macrostrat units and the lithologies that they contain are stored as dictionaries in separately managed database tables that also contain related information, such as hierarchy (e.g., sedimentary rock includes carbonate, carbonate in- 


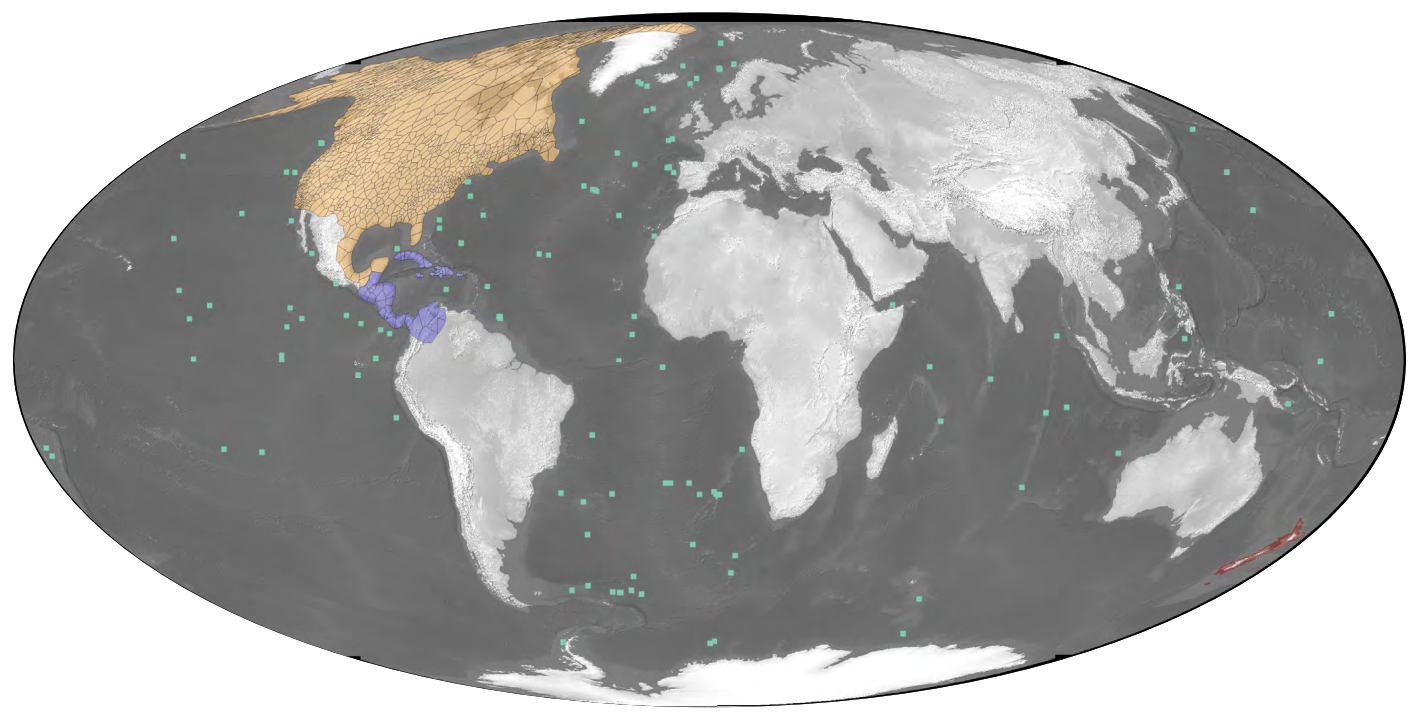

FIG. 2. Geographic distribution of columns, segregated by project (North America, Caribbean, New Zealand and deep sea), in the current public version of the Macrostrat database. Columns located on continental crust acquire, by default, a geographic footprint that is defined by a Voronoi tessellation. The points used to create the tessellation correspond to the approximate center of the region covered by each composite column. It is possible to edit the spatial topology of columns in order to align their boundaries with geologically meaningful features. Macrostrat columns from the deep sea are assigned point coordinates based on the offshore location of each drilling site. For consistency with continental columns, offshore drill sites are represented by rectangular buffers around those points.

cludes grainstone) and synonyms (e.g., "dolostone" is an alternative name for "dolomite"). All Macrostrat units have at least one dominant lithology, but multiple lithologies, and the relative volumetric abundances of each, can be recorded for each unit. Thus, one way of improving existing Macrostrat data is to refine the lithological information that is linked to units, either by providing additional lithologies or by adding more detailed attributes to lithologies (e.g., "stromatolitic dolostone" rather than "dolostone").

Each Macrostrat unit is treated as a distinct entity that is associated with only one column, regardless of whether or not the geological object that a unit represents can be traced laterally between multiple adjacent columns. Columns are, therefore, equivalent to independent samples of the upper crust. This design allows spatial variability in the attributes that are assigned to "units," such as lithostratigraphic names, to be captured. For example, a widespread time-transgressive lithostratigraphic rock unit would be intersected by multiple Macrostrat columns and the age of the corresponding units assigned to that lithostratigraphic unit in each column could be different, reflecting its time transgressive nature. In this case, only the lithostratigraphic name applied to the units would identify them as related in some way (thereby demonstrating the poor time-correlation value of that particular lithostratigraphic term). Similarly, a single rock body that varied spatially in thickness and lithology would be represented by multiple units with different such attributes in each intersecting column.

The primary grouping criteria for Macrostrat units is their assigned geographically-defined column, but units within a column are also grouped into "packages" (also known as "sections") on the basis of temporal and ge- netic continuity that is defined at the time of data entry. Package structure can also be calculated dynamically depending on the criteria that are used to define units of interest and the gaps that separate them (see above). An advantageous approach, then, is to create columns with the finest possible temporal and lithological resolution, which allows packages to be defined and analyses to be conducted at any arbitrary scale.

Macrostrat has dictionaries of known terms, including lithologies, attributes that modify lithologies (e.g., "bioturbated sandstones"), environments, minerals, measurement types, chronostratigraphic time intervals, and lithostratigraphic names. However, Macrostrat does not attempt to be prescriptive about how individual units are described. Doing so would effectively prohibit the use of a large fraction of the published primary field descriptions and data. Instead, Macrostrat attempts to capture the language that has been used to describe the rock record and to then link those descriptions back to a physicallyand, at least in principle, objectively-defined portion of the upper crust. Ambiguity, uncertainty, and inaccuracy is, therefore, expected in some cases. Insofar as descriptions of rocks and the data extracted from them can be geographically located and linked to a physically recognizable rock body, Macrostrat can help to organize observations and to recognize and resolve inconsistencies. The overarching goal is to arrive at a working and inclusive description of the upper crust that will continue to be refined as newer and better information and data are incorporated. 


\section{B. Columns}

The geographic columns that contain Macrostrat units are of two basic types: 1) those that represent a precisely located and discrete sample of the upper crust, like those supplied by boreholes in offshore drilling sites from the Ocean Drilling Program, Deep Sea Drilling Project, and International Ocean Discovery Program, and 2) those that represent a composited summary of the geology over a geographic area (e.g., refs. 36-40). Both data types have advantages and disadvantages. For example, composited geological columns, by definition, capture units with limited geographic extents that would likely be missed in single boreholes. Regionally composited columns, on the other hand, lack information about the specific spatial distribution of geographically restricted units and often lack clearly defined vertical positions (in space) for units.

Macrostrat currently consists of four major groups of columns that are separated, for convenience, by geographic region (Fig. 2). Columns are assigned to "projects" that identify groups of columns, some of which might share primary source reference(s) or compilation approaches. For example, the deep sea data set consist entirely of core descriptions compiled from offshore drilling sites ${ }^{41,42}$, whereas the continental record in North America consists of regionally composited geologic columns. Because the latter typically lack precise definitions of geographic extent, the boundaries between all such composited columns in Macrostrat are interpolated using Voronoi tesselation and a manually constructed bounding geometry. The boundaries of Macrostrat column polygons could be modified to reflect actual geological provincial boundaries, major structural discontinuities, and other geographic and geologic features, but doing so requires additional geospatial data to define relevant boundaries and/or manual effort to adjust the initial tesselation-based geographic footprint for columns.

\section{Geochronological Time Intervals}

Chronostratigraphic time intervals (e.g., biozones, ages, periods) are stored in Macrostrat and related to one another and to numerical ages in both relative and absolute senses. Chronostratigraphic intervals that have actual numerical age estimates, principally those provided by the International Commission on Stratigraphy for Global Stratotype Boundary Section and Points (GSSPs; ref. 43), are referenced to absolute time (subject to explicit uncertainties and future revision). Chronostratigraphic intervals for which there are no direct numerical age constraints are not assigned numerical ages. Instead, intervals lacking direct geochronological constraints are assigned boundaries with positions that are defined relative to another chronostratigraphic interval (e.g., a boundary for a chronostratigraphic bin could be referenced to $25 \pm 5 \%$ of the duration through an international age, which is in turn referenced to boundaries that do have absolute numerical age estimates, such as GSSPs). This approach to managing geochronological time intervals and their numerical ages obviates a need to associate each interval with an explicit stored numerical age(s) and makes the actual numerical age constraints more transparent. This approach also has a data management advantage: when the numerical age of a chronostratigraphic interval is modified, that change is propagated to all relevant correlated time intervals.

Chronostratigraphic time scales (e.g., international ages and periods, biozonations, regional chronostratigraphic subdivisions) and reference information for each timescale are also stored in Macrostrat. However, because a chronostratigraphic time scale is essentially a group of individual named time intervals, timescales are only indirectly referenced to intervals (in much the same way that units are only indirectly referenced to columns via a join in the database). This approach allows a one-to-many relationship between time intervals and the timescales that use them (i.e., the Rhaetian is an international age, as well as part of the North American regional timescale), which in turn enables the creation of custom time scales from existing time intervals.

\section{Continuous-Time Age Model}

Each Macrostrat unit that is not directly associated with a geochronological measurement (e.g., a radioisotopically dated ash bed) acquires an initial modeled numerical age by applying basic correlation approaches and by using contact relationships with other units in the same column. Because the units that comprise Macrostrat columns are often shorter in duration than the chronostratigraphic time bins to which they can be correlated, basic laws of superposition allow time to be distributed more finely within and between units than bin-based correlations. This means, for example, that Macrostrat's continuous-time age model is capable of predicting the age of an ash bed before the relevant measurement is made. In the case of a numerically-dated unit, its boundaries are referenced to an absolute position in time, with uncertainty. These chronological "spikes" anchor the chronological position of the bed and serve as constraints in an incrementally-improving age model.

Although capable of incorporating direct numerical age estimates, the preliminary age model for Macrostrat was constructed for each column using only the chronostratigraphic bins to which its constituent units were originally correlated and the relative temporal constraints provided by contact relationships of adjacent rock bodies within columns. For example, if there were 10 vertically stacked sedimentary units assigned to one continous package (units are always assigned to only one column), and if together those units spanned completely one chronostratigraphic time bin (e.g., the Frasnian), then the absolute time represented by that chronostratigraphic bin would be distributed in a relative sense equally and sequentially between each successive unit. The oldest unit would have a bottom age equal to the base of the chronostratigraphic bin (i.e., 0\% of the way through the Frasnian), the youngest unit would have a top age equal to the top of the chronostratigraphic bin (i.e., $100 \%$ of the 


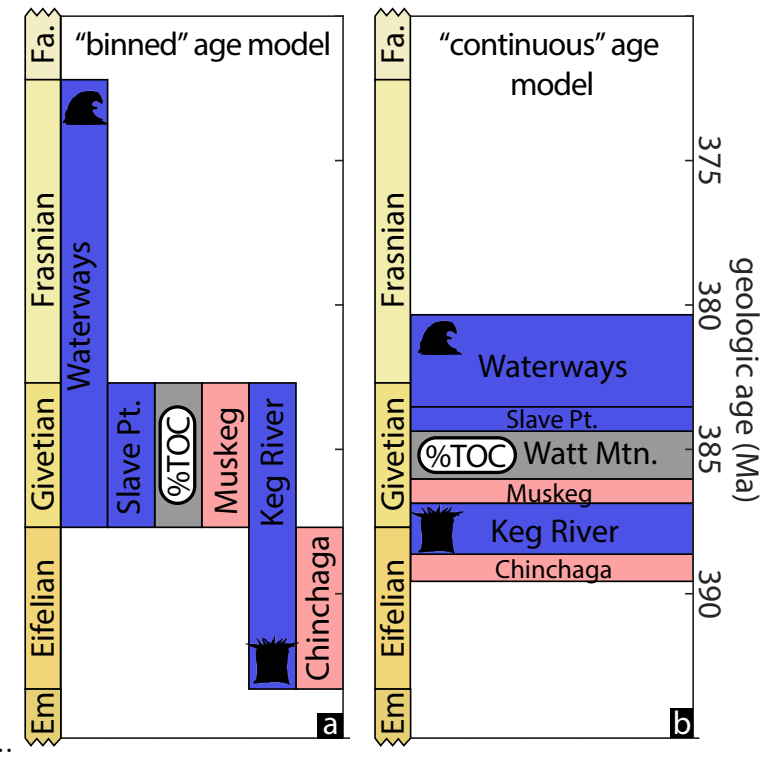

FIG. 3. Illustration of "binned" (a) versus "continuous" age model (b), using an end-Devonian gap-bound packaged from the Zama Lake column in northern Canada. In this example, units were originally correlated to one or more epochs (a). Using superposition (i.e., Chinchaga is overlain by Keg River, etc.) and more refined opinions about the correlation of units to a chronostratigraphic time intervals (i.e., the top of the Waterways Formation is found in the lower half of the Frasnian), the result is an internally-consistent continuous age model (b). The boundaries of units have identity and serve as the basis for age assignments in Macrostrat.

duration through the Frasnian). Unit boundaries between these two stage-defining tie points would be distributed equally and proportionally within the chronostratigraphic bin (e.g., the top of the first unit/bottom of second unit would be at position equal to $10 \%$ of the duration of the Frasnian, the top of the second unit/bottom of the third unit would be at a position equal to $20 \%$ of the duration of the Frasnian, etc.). Because Macrostrat columns are regionally composited, it is not uncommon for there to be coeval units in a single column (i.e., there are "laterally adjacent" units that reflect spatial variation in lithology within the geographic region covered by the column). In such cases, units in the same column will have overlapping ages in the age model.

Macrostrat's initial age model uses the fewest possible parameterizations (i.e., correlation to chronostratigraphic time intervals and superposition) to arrive at an internally-consistent continuous-time age model (Fig. 3). As a result, the model lacks explicit statements of uncertainty and does not take advantage of all other information that could be temporally informative, such as thickness and lithology. However, the age model is readily improved. Data produced by geochronological laboratory facilities, for example, can be incorporated into Macrostrat's age model and then propagated to all data resources linked to it (e.g., a radioisotopically-dated ash bed within a Macrostrat unit would automatically constrain the ages of all fossil and geochemical samples linked to that unit and adjacent units, as in Fig. 3). Additional approaches to correlating and constraining ages, includ- ing, for example, constraints from event ordination ${ }^{44}$ and astrochronological tuning (e.g., ref. 45).

By incorporating numerical age estimates into a comprehensive framework describing the rock record, geochronological lab facilities can readily acquire broader geological context for measurements and help to prioritize effort by identifying geographic or temporal portions of the rock record that could benefit the most from new measurements. Because the unit-based architecture of Macrostrat can accommodate any arbitrary scale of partitioning, including a dated horizon in a sedimentary unit requires only dividing the containing unit into the dated horizon and adjacent components (e.g., a dated ash bed from the middle of a single Macrostrat unit would require division of that unit into three portions, the portion of the unit below the bed, the bed itself, and the portion of the unit above the bed). The new dated horizon would then serve as a "spike" constraint on numerical age, with analytical error.

\section{E. Lithostratigraphic Names and Hierarchies}

Macrostrat manages the names that are assigned to rock units (e.g., lithostratigraphic members and formations) in three ways. First, "concepts" are used to designate groups of names that identify the same entity. For example, the "Dakota" concept applies to lithostratigraphic names of formation rank, including the "Dakota Sandstone," "Dakota Formation," and "Dakota Conglomerate." The stratigraphic concept of "Dakota" also applies to a lithostratigraphic name of group rank, the "Dakota Group." All four of these lithostratigraphic names and ranks are separately stored in Macrostrat but they are also all identified as belonging to the same lithostratigraphic concept: "Dakota." Concepts are also associated with additional information, including descriptions of usage, geologic age, general lithological and/or temporal properties, geographic region, and source reference. The overall structure of the concept component of Macrostrat's lithostratigraphic nomenclature is comparable to the USGS Lexicon ${ }^{46}$.

In addition to grouping lithostratigraphic and other rock-body names that refer to the same geological entity, Macrostrat explicitly stores nomenclatural hierarchy. For example, the "Dakota Formation" (one of the names and ranks used in the "Dakota" concept) is the parent of four member-level lithostratigraphic names. Explicit storage of nomenclatural hierarchy makes it possible to access Macrostrat data from any nomenclatural starting point and to then automatically obtain all of the parent and child lithostratigraphic names and their variants, as well as the rock units to which they are applied in space and time.

Currently, more than 36,000 lithostratigraphic names are stored in Macrostrat, most of which derive from modified versions of the USGS National Geologic Map Database, Australian Lexicon, Canadian Weblex, and British Geological Survey Lexicon stratigraphic lexicons, as well as other external resources. Reference to these sources and URLs linking back to original Lexicon data 
pages are provided for concepts wherever possible, but most of the relevant information associated with stratigraphic names is also available from within Macrostrat.

Lithostratigraphic names are notorious for lacking chronostratigraphic significance and, in some cases, for dizzying historical convolutions. However, this fact does not diminish their prevalence in the published literature or their usage on geologic maps, the field books of geologists, and museum specimen labels. Lithostratigraphic names are, in many regions of the world, the lingua franca for parts of the rock record that are, at least in principle, readily recognizable in the field. Macrostrat's data structure is capable of storing lithostratigraphic terms and doing so in a way that exposes their spatiotemporal disparities and inconsistencies. Indeed, the ability of Macrostrat to provide a quantitative space-time index of lithostratigraphic nomenclature is one of the informaticsrelated strengths of the database (see below).

Like most components of Macrostrat, there remain ambiguities and errors in the nomenclatural hierarchy and assignments of names to Macrostrat units. For example, it is possible for some lithostratigraphic homonyms to not be resolved properly as synonyms. Such ambiguities and errors are readily fixed when they are discovered, and any changes made to the database propagate automatically. Just as the field of geology (and all empirically-grounded science) remains in a constant state of refinement and improvement, none of the information in Macrostrat should be viewed as static. The database continues to improve as human expertise is applied to the process of data curation and as new constraints on and hypotheses for the chronology and physical properties of the upper crust emerge.

\section{F. Geologic Maps}

Bedrock geologic maps are working hypotheses for the surface expression of physical, three dimensional rock bodies and structures in the upper crust that are typically derived from a combination of aerial imagery and fieldbased measurements and observations. A continuous spatial model is then generated from these observations using widely accepted (but heterogeneously applied) methods and criteria ${ }^{47,50,51}$. Similar to Macrostrat columns, which constitute working hypotheses for the chronological distribution of rock bodies that can be refined by the addition of new constraints, new field data and observations can result in revisions of a geologic map. Maps (and Macrostrat columns) are, therefore, more akin to model output than they are to primary data. Nevertheless, geologic maps are useful starting points for framing geological field problems and for motivating additional data collection and hypotheses. They can also serve as useful data in their own right ${ }^{7,20,52-54}$. Many of the pamphlets and legends accompanying geological maps also contain detailed field descriptions of rock units that are difficult to discover and are therefore underutilized. One objective of the geologic map component of Macrostrat is to rectify this situation and to expose the information behind geological maps to a wider range of uses, ranging from the facilitation of geological field work to machine reading and data synthesis tasks.

All bedrock and surficial geologic maps consist fundamentally of geospatial polygons and, optionally, lines and points, all with associated attributes. Polygons represent geologic map units, believed by the authors to have some physical and/or genetic continuity. Lines represent faults, fold axes, dikes, marker beds, and other surface-expressed lineaments. Points describe the location of fabric orientation measurements (e.g., foliation and bedding strike-dip) or other measurements (e.g., paleocurrent directions) or location-specific observations (e.g., mineral/fossil occurrences). Macrostrat's PostGIS geological map database stores three groups of information for all bedrock and surficial geological maps: 1) the original vector-based map objects (polygons, lines, and points) and their attributes, 2) standardized representations of maps that capture elements common to all geological map objects (see below), and 3) tables that store intersections of geological map objects and Macrostrat entities (i.e., units, lithologies, lithostratigraphic names, chronostratigraphic intervals).

The original sources that supply bedrock and surficial geologic map data are heterogeneous in all respects, including digital vector file formats (e.g. shapefiles, ArcInfo Coverages, File Geodatabases) and the conventions used to represent and store geometries and their attributes. By simply ingesting geological map data into a common GIS environment, a new synthetic dataset with wide utility is created. Going one step further by harmonizing map data into a basic but common core structure (defined by general field type, not by prescriptive field contents, see below) requires some effort, but it is also a straightforward task. Currently, Macrostrat's harmonized map database is logically partitioned into four arbitrary map scales (Fig. 4) for convenience and to enhance the query performance of the system. Despite this scale-based separation at the database-level, each polygon, line, and point ingested into the harmonized dataset acquires an internally-unique identifier and maintains key-based links back to all original map data.

In order to be included in Macrostrat's harmonized geologic map system, an original map source must have polygons in vector format and those polygons must include at least basic information about age and general lithology. Additional, sometimes lengthy, descriptions are also accommodated, including map unit names and text-based descriptions and comments pertaining to them. It is often necessary to transcribe the contents of accessory publications (e.g., map unit descriptions in separately provided PDFs) into the GIS environment in order to fully leverage the information. In some map sources, lithologies are explicitly separated from descriptions, in others, the text-based descriptions include lithologies. Both conventions are accommodated and the first step twoards standardization is arrived it through simple string-based matching using Macrostrat lithology definitions. The only data that are rigidly standardized among all maps are lithostratigraphic nomenclature ("clean" versions of formal names are inserted into a specific field, regardless of how those names are formatted/represented in the original data) and numer- 

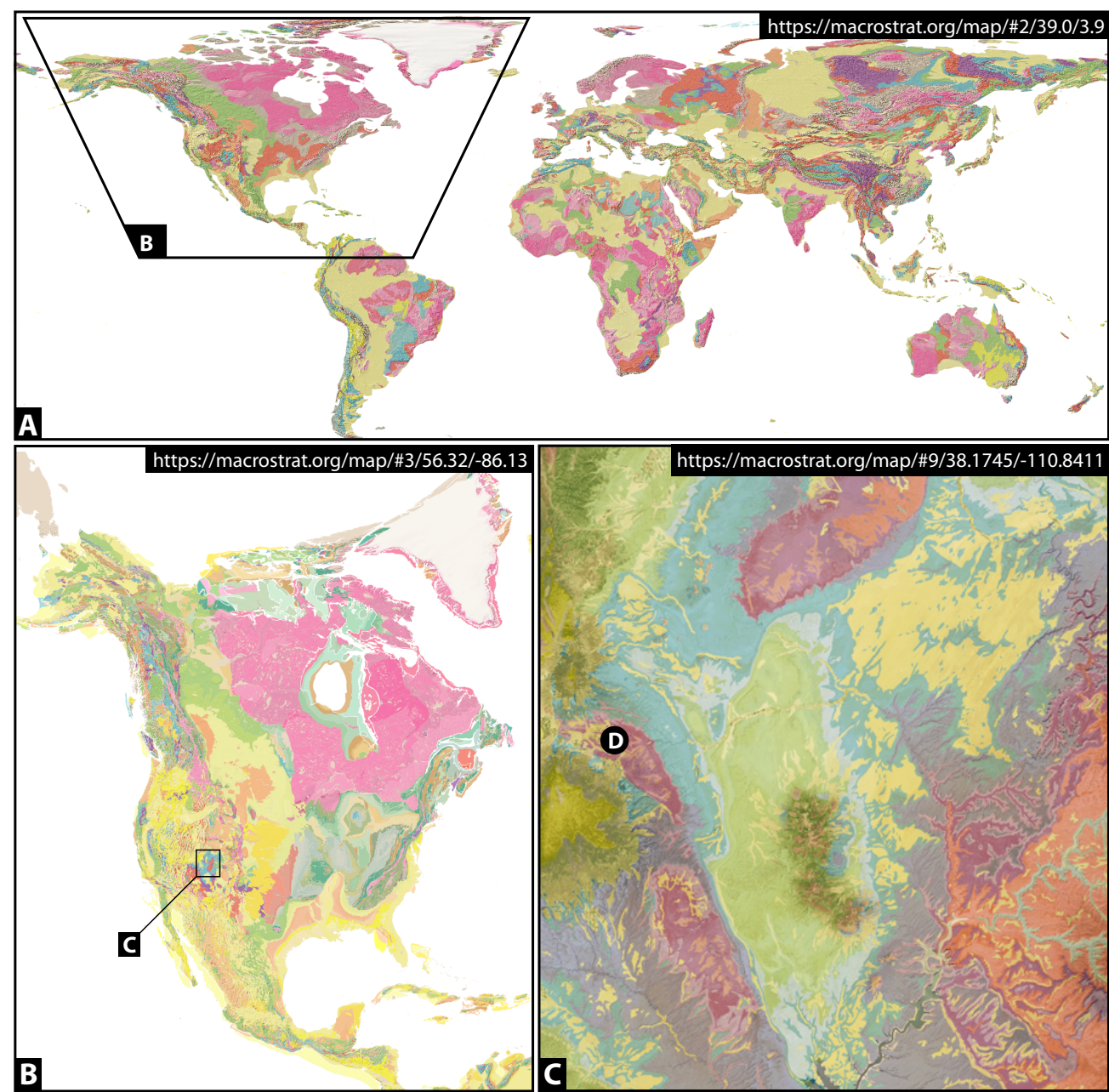

\begin{tabular}{|l|l|l|}
\hline Triassic (1) sedimentary rocks in Salt & Moenkopi Formation & Journal of Geophysical \\
southeastern Utah & Age: Scythian - (252.17- 247.2 Ma) & Research Wiley \\
Age: Early Triassic (252.17 - 247.2 Ma) & Thickness: 0 - 600m & Lienert, Barry R., Helsley, C. E., 1980. \\
Stratigraphic name: Moenkopi Formation & PBDB Collections: 20 & Magnetostratigraphy of the Moenkopi \\
$\begin{array}{l}\text { Comments: fluvial, mudflat, sabkha, shallow marine; } \\
\text { redbeds }\end{array}$ & Unit ID: 14778 & Formation at Bears Ears, Utah. \\
$\begin{array}{l}\text { Lithology: Major:: \{mudstone\},Minor:: \{sandstone\},In- } \\
\text { cidental:: \{siltstone, limestone, evaporite, conglomer- } \\
\text { ate\} }\end{array}$ & Reference: Macrostrat.org & Earth and Planetary Science \\
$\begin{array}{l}\text { Reference: USGS compilers, 2005, State geologic map } \\
\text { data: State Maps. 1060836. }\end{array}$ & & $\begin{array}{l}\text { Letters Elsevier } \\
\text { Bressler, Stephen L., Elston, Donald P., 1980. } \\
\text { Declination and inclination errors in } \\
\text { experimentally deposited ... }\end{array}$ \\
\hline
\end{tabular}

FIG. 4. Geological maps at multiple scales and their accessibility from and integration with Macrostrat. A, Generalized geological map of the world ${ }^{47}$. B, Geologic Map of North America ${ }^{48}$. C, Geologic map of Utah ${ }^{49}$. D, Result summary obtained by clicking on map at location of point D. A summary of some of the original map data is shown in left panel; middle panel contains Macrostrat-derived data matched to that map polygon; right panel shows example literature data obtained by using stratigraphic name to identify content in the GeoDeepDive infrastructure (https://geodeepdive.org).

ical ages (the time intervals assigned to map units are maintained, but all numerical ages derive from Macrostrat chronstratigraphic interval definitions).

Lines (e.g., faults, dikes, fold axes), are not required for a map source, but when they are present, a similar convention is followed when standardizing structure between maps. Long-form original descriptions, when applicable, are preserved but a standardized field describing line type (e.g., "normal fault") is designated or created. One problem that is unique to lines is the asymmetry that they often have (e.g., the side of a line that the "teeth" ap- pear on in a thrust fault, which indicate the over-riding block). There are no widely-used protocols for identifying such asymmetries on vector lines and most map sources do not contain any direct digital information. Macrostrat's standardized line structure does allow for the specification of line asymmetry (by convention, the point defining the start of the line is the reference point), but most sources require manual revision, and that process can remain incomplete for maps. Points (e.g., foliation or bedding strike-dip, lineation trend-plunge, mineral occurrence) are also optional data for each map. 


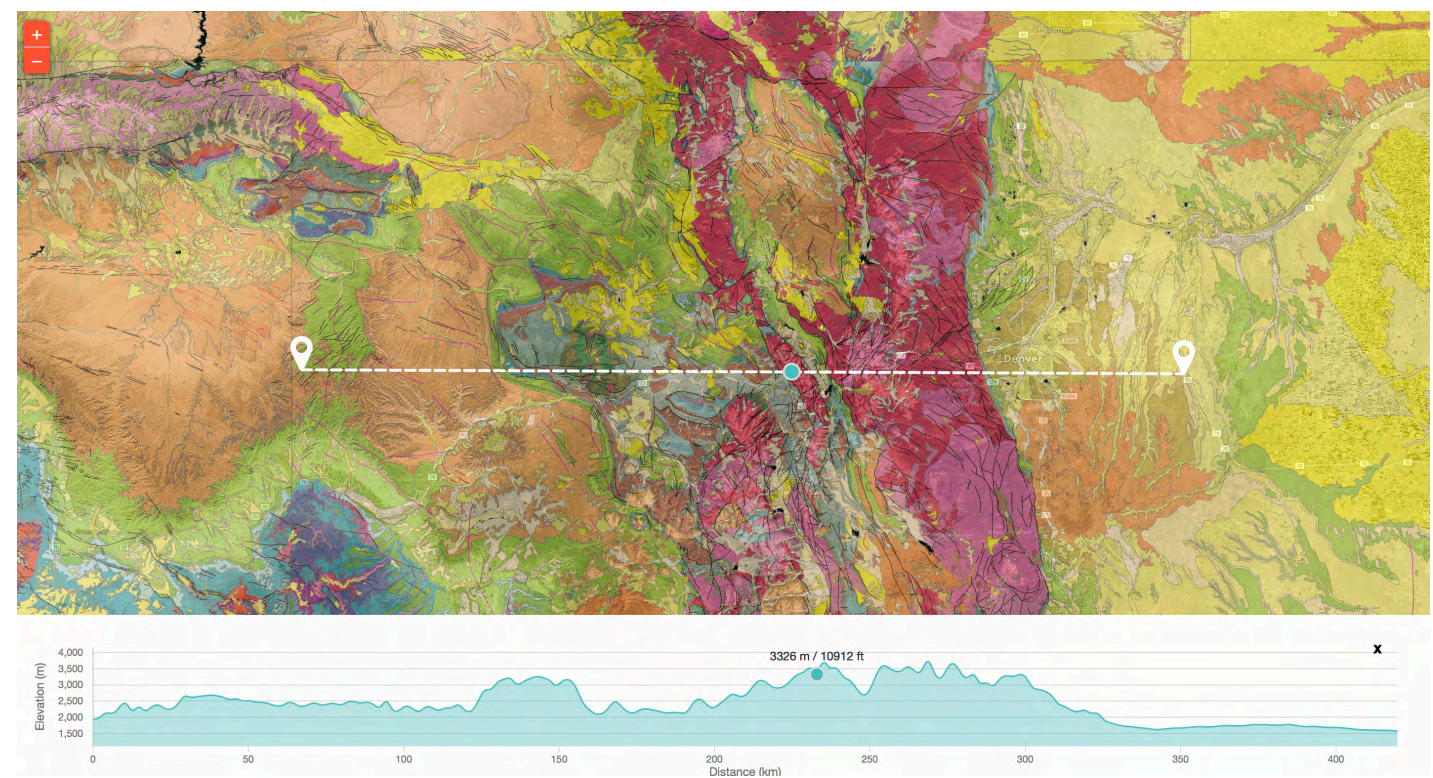

FIG. 5. Elevation profiles along lines can be dynamically generated by clicking on two points on Macrostrat's geologic map, accessible at https://macrostrat.org/map.

Standardization of point data typically involves assessing/verifying conventions for dip direction (e.g., implicit use of a "right-hand rule") and normalizing descriptions of point types (e.g., "bedding").

After a map's polygons and, optionally, lines and points, have been imported into the standardized database, links between geologic map objects and Macrostrat objects (units, lithostratigraphic names, lithologies, etc.) are established using a combination of spatial and temporal intersection and simple string matching (Fig. 4d). The link between map polygons and Macrostrat units is the most complicated step, as it involves: 1) analyzing the strings that are used to name rock units (a step that is informed by the nomenclatural hierarchies stored in Macrostrat), 2) quantitatively assessing the spatial intersections/distances between Macrostrat units and geological map objects, and 3) testing for overlap in the stated geological ages of each. A geologic map polygon and a Macrostrat unit that overlap in all three attributes (geography, age, name) constitutes the highest confidence match. Relaxing one or more of these congruences might reduce confidence in the match, but it may still be valid (e.g., a Macrostrat unit and a geologic map polygon may not intersect spatially, but they may be within $75 \mathrm{~km}$ of overlapping and share all other attributes, making them highly probable matches). Matches between Macrostrat units and map polygons, and the basis for them, are made algorithmically, but it is also possible to manually remove and add matches.

Although explicit links between geologic map polygons and Macrostrat units can have ambiguity (e.g., due to differences in the way lithostratgraphic units are grouped in a map source vs. in Macrostrat), the process is streamlined and the results are repeatable. There also tends to be a large amount of agreement between geologic maps and Macrostrat units because the language that is used to describe rocks in the field is often consistent, at least over the past several decades in many areas of North America. Because spatial expression of rock units is (at least in principle) more objectively defined than estimates of their age or interpretations of their origin, many potential ambiguities that could occur are removed by quantitative tests for spatial and basic descriptive overlap. The end result of matching map units to Macrostrat column units benefits both data sets. Geological map polygons inherit the relevant Macrostrat unit(s) modeled ages (Fig. 3), which are often much more precise than the epoch or longer interval geochronological intervals that are commonly designated on geological maps. Similarly, any other data that have been linked to a Macrostrat unit, such as PBDB fossil occurrences or paleocurrent measurements ${ }^{55}$, can be inherited as attributes of map polygons. Macrostrat units, in turn, benefit by acquiring new information about field properties, such as constraints on their surface expression and more complete, first-hand descriptions of lithology and other attributes.

Macrostrat's geologic map coverage is globally complete at the smallest map scale (Fig. 4a), but larger scale coverage is patchy geographically, and it will always be so because that is the nature of the way geological maps are produced. Nevertheless, there are currently some 2.1 million geologic map polygons from more than 170 distinct sources globally integrated in a seamless "Google Maps"-like environment (see for a complete listing and spatial index). More than 15,000 Macrostrat units in the regions covered by columns (Fig. 2) have been matched to bedrock polygons. The process of adding new geological map data and linking relevant data to Macrostrat is efficient. Once a map is added to the system, validated, and then transferred to the primary server, all data automatically propagate throughout the entire system (e.g., all new map data automatically show up in the web-based map viewing application accessible at https://macrostrat.org/map, as well as third-party applications). 


\begin{tabular}{|c|c|c|}
\hline Route & Formats & Description \\
\hline /columns & json,csv,geojson & $\begin{array}{l}\text { search and summarize columns based on unit properties } \\
\text { or geographic location }\end{array}$ \\
\hline /sections & json,csv & summarize units by gap-bound packages \\
\hline /units & json,csv,geojson & search and summarize units based on their properties \\
\hline /defs/lithologies & json,csv & rock types and hierarchies \\
\hline /defs/lihtology_attributes & json,csv & modifiers applied to rock types \\
\hline /defs/environments & json,csv & depositional environments and hierarchies \\
\hline /defs/strat_names & json,csv & lithostratigraphic names and hierarchy \\
\hline /defs/strat_names_concepts & json,csv & grouping, attributes and sources for strat_names \\
\hline /defs/intervals & json,csv & chronostratigraphic time intervals \\
\hline /defs/timescales & json,csv & chronostratigraphic timescales \\
\hline /defs/measurements & json,csv & measurements and measurement groups \\
\hline /defs/minerals & json,csv & mineral names and chemistries \\
\hline /geologic_units/map & json,csv,geojson & geologic map data for lat-lng coordinate or stratigraphic name \\
\hline
\end{tabular}

TABLE I. Select Macrostrat API routes available in version 2. Each route described here is preceded by the base URL https://macrostrat.org/api/v2, which also returns this table in expanded, JSON format. Omitting a version in the base URL (i.e., v2) defaults to the latest version of the API. The version number should be included in the URL to ensure that a given API call behaves consistently as the API is updated and modified. For information on parameters accepted by each route and its response, visit the base route route (e.g., https://macrostrat.org/api/v2/defs/lithologies).

Expanding and improving the geological map dataset is currently limited by the time required to find, download, and import geological maps into Macrostrat's GIS environment. Some geological maps have also not yet been made publicly available in a vector-based format or, if the data are available, they are not public or have licensing terms that prohibit their modification and reuse. The latter is particularly regrettable because geological maps are usually produced with public funds and represent important, basic geological field data that are often underutilized.

\section{G. Topographic Data}

Geological map units are intimately connected to Earth's surface topography. For this reason, we have integrated NOAA's ETOPO1 ${ }^{56}$ and the most recent release of NASA/JPL's Space Shuttle Radar Topography Mission (SRTM) data ${ }^{57}$ into the Macrostrat geological map infrastructure. It is notable that both elevation data sets are raster-based, rather than vector based, illustrating that Macrostrat (by virtue of its GIS underpinnings) is capable of harnessing any type of geospatial data. Elevation can be readily intersected with all other Macrostrat data (e.g., bedrock geologic maps). Although not yet extensively utilized in Macrostrat's public applications, topographic data are accessible in basic capacities within the mobile application, Rockd, described below, and within Macrostrat's map web interface (Fig. 5).

\section{H. GPlates Paleogeographic Rotations}

Paleogeographic context is critical to many questions in historical Earth systems science ${ }^{58,59}$. Geological data, in turn, provides fundamental constraints on paleogeographic reconstructions ${ }^{60,61}$.

Using GPlates software and associated rotation mod- els from various authors ${ }^{60,62-66}$, we are able to provide a working paleogeographic hypothesis for all Macrostrat and Macrostrat-linked data, such as maps and fossil collections. Our infrastructure deploys these rotation models using the PyGPlates Python package. This software enables us to rapidly apply different reconstruction models and ages to myriad data, and is currently used as a web service that powers the paleogeographic view in Rockd (see below). Eventually, we hope to develop more efficient methods for paleogeographic reconstructions that allow for dynamic rotations of complex features such as geologic map polygons.

\section{Application Programming Interface (API)}

Database design is a critically important component of any data infrastructure that impacts the efficiency and reliability of data entry, editing, and retrieval. Most of Macrostrat's data, outlined in general terms above, are stored in approximately third normal form (see Fig. 6 for a simplified schematic). However, modern methods of accessing data that are housed on remote repositories typically do not require any detailed knowledge of database design or software. APIs provide a set of tools for building software, and in the context of databases, they provide a specification for how to make remote requests for data using a standard protocol (usually HTTP) and a parameterization that does not depend upon knowledge of underlying database software, schemas, or serverexecuted code. The remote server's responses to requests are also formatted using standards that are not specific to any one end use. The general principles governing the deployment of APIs vary, but most modern examples follow a Representation State Transfer (REST, ref. $67)$ model. Although there are few widely agreed upon implementation details of a REST-ful system, one of the primary principles is the identification of data resources using Uniform Resource Identifiers (URIs), for example: 


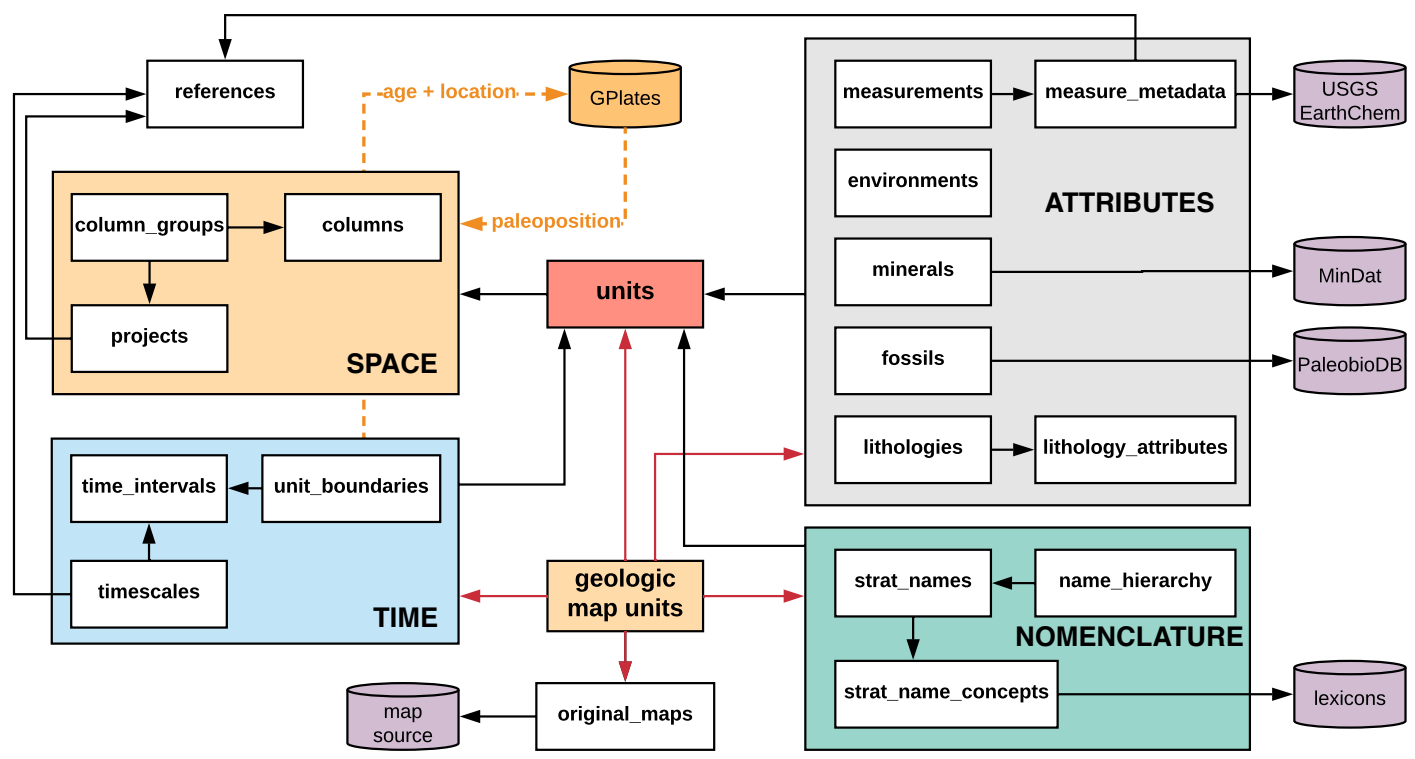

FIG. 6. Simplified schematic of core database elements and their relationships in Macrostrat. Columns (as in Fig. 1) store spatial data and group one or more units. Purple cylinders represent external database resources. Orange cylinder represents GPlates paleogeographic rotation model. Intermediate join tables as well as other internal tables, relationships, and table fields are omitted for clarity.

\section{https://macrostrat.org/api/v2/defs/strat_ names?strat_name=waldron\&rank $=\mathrm{fm}$}

This URL returns metadata that is specific to the API (version number and data license), along with relevant data, which in this case is basic summary information for all lithostratigraphic names of formation rank that have a name string matching "waldron." Lithological nomenclatural concepts, as described above, are a different object and therefore have a different URL, for example:

\section{https://macrostrat.org/api/v2/defs/strat_name_ concepts?name=waldron}

This returns data for all lithostratigraphic concepts with names matching the string "waldron" (case insensitive) including a unique identifier for each concept and additional information about age, usage, source information, and any available links back to original resources (e.g., USGS Lexicon).

Most responses returned by the Macrostrat API are, by default, formatted in JavaScript Object Notation (JSON), a platform-independent, open standard format. Responses formatted as comma-separated values (CSV) can also be obtained for most routes by adding the parameter "\&format=csv" to the URL. Routes returning geographic objects (i.e., points, lines, and polygons) can also be formatted as GeoJSON or TopoJSON by supplying an appropriate "\&format=" parameter.

Basic documentation for each route in the Macrostrat API is accessible by invoking the base URL. For example, general information about the Macrostrat API as a whole and all available routes are returned, in JSON format, by https://macrostrat.org/api. The base URL of each listed route (e.g., https://macrostrat.org/api/ columns) similarly returns simple documentation that is specific to the given route, including accepted parameters, available response formats, and brief explanations for the returned fields and their values.

API requests can be generated, made, and processed programatically in any programming or scripting environment that is capable of making and receiving HTTP requests. Examples of such environments currently in wide use among geoscientists include R, Python, and MATLAB. Figure 7a shows one such example in which the abundance of coal is quantified as a time series in Matlab by requesting the appropriate data via the Macrostrat API and plotting it using Matlabs built-in plotting functions (with additional customizations). To make this figure, North American units that are identified as containing any amount of organic sediment are first requested by properly-formatting a URL:

\section{https://macrostrat.org/api/v2/units?lith_type= organic\&project_id=1}

The continuous-time modeled ages of the units are used to define gap-bound package structure in each column in this instance, defined as the number of unique columns occupied by coal units in 1 Myr plotting increments. For convenience, Macrostrat includes an API route that generates such package summaries for the specified subset of units (https://macrostrat.org/api/sections?lith_ type=organic). For geological discussion of these results and their pertinence to our understanding of the mechanisms for Paleozoic coal formation, see ref. 68 .

Owing to Macrostrat's integration with paleogeographic data and models (see above), the latitudinal distribution of organic-rich units could also be analyzed as a time series (Fig. 7b). In this instance, the long-form API response would be required because paleogeographic rotations are not included in the short-form API response 

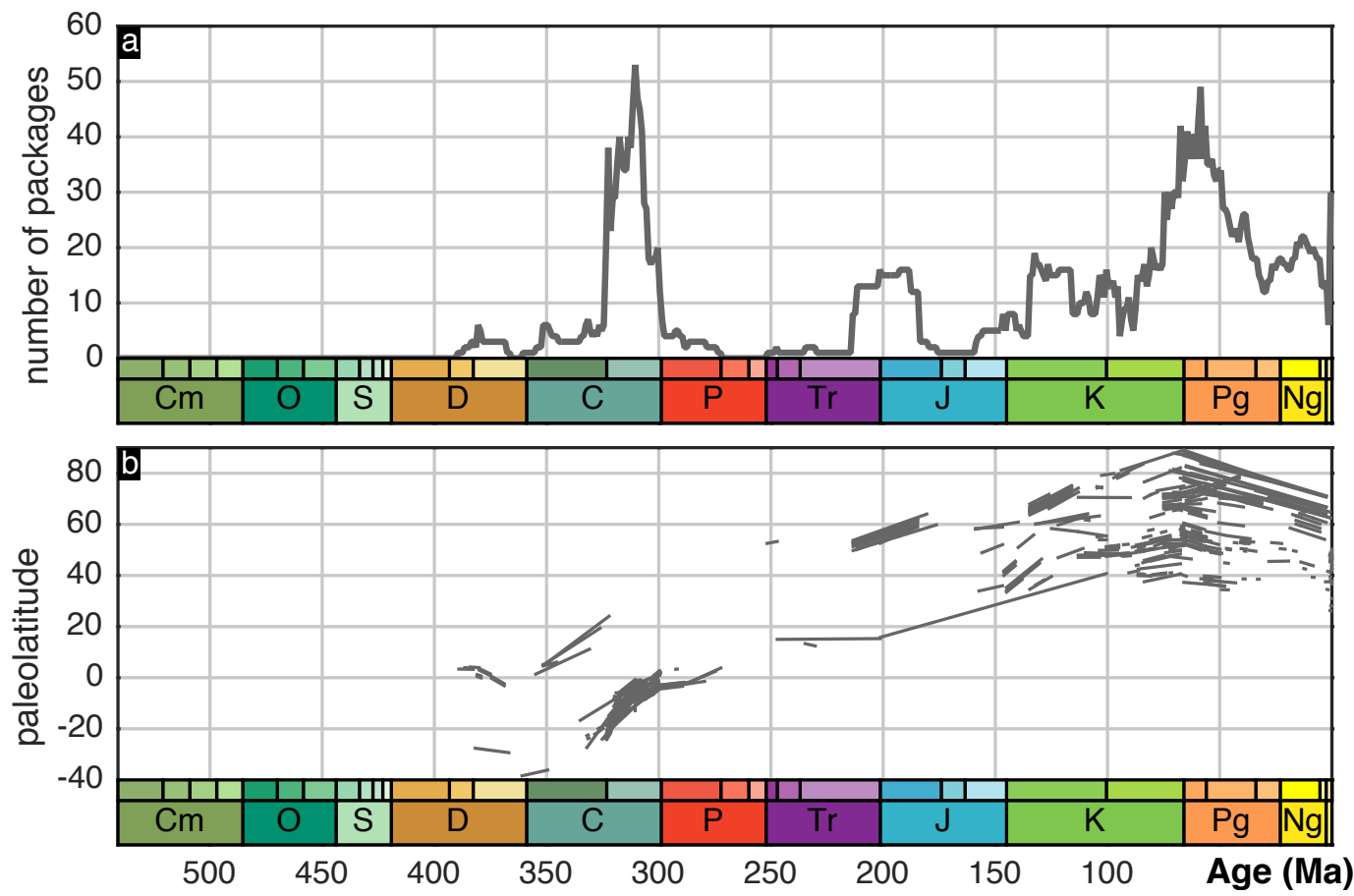

FIG. 7. (a) Time series showing the number of organic sediment-bearing packages, a result published and discussed in ref. 68 . (b) Paleolatitude vs. time for organic-rich sediments. Each line segment shows the latitudinal position over the duration of a sedimentary unit containing organic-rich sediments.

(to allow the most basic and commonly-used data to be retrieved with the lowest network overhead possible):

https: //macrostrat.org/api/v2/units?lith_type=
organic\&project_id=1\&response=long

The Macrostrat API can also be used to obtain other relevant data, such as international chronostratigraphic period names, abbreviations, ages and their conventional colors. This API call is in fact used to generate the graphical timescales in Fig. 7. The Macrostrat API can also be used to supply data in a GIS environment. Figure 8 shows one such example in the free software application QGIS. Data from three separate API calls, corresponding to the three features shown on the map, are represented: columns containing Late Jurassic shale (gray polygons), outcrop expression of the Morrison Formation (red polygons) from geologic maps, and Late Jurassic Paleobiology Database fossil collections (blue dots) that have been matched to the relevant Macrostrat units. The API URLs are shown at the top of figure 8; the bottom panel illustrates where URLs should be called within QGIS to add each feature, Middle panel shows the resulting map.

\section{EXAMPLE APPLICATIONS}

The power of APIs is that they allow the same data to be analyzed and displayed in many different ways. Several mobile and web applications that use the Macrostrat API are now publicly available, including the iOS and Android application Flyover Country and the iOS application Mancos, each developed by third parties. Here, we briefly describe the Rockd mobile application developed by the Macrostrat group.

Rockd (https://rockd.org) is an iOS and Android application, built using the Ionic framework, that leverages Macrostrat's geologic map data as well as lithostratigraphic nomenclature, lithologies, paleogeographic reconstructions, and other location-specific information. One of the fundamental questions that Rockd aims to help users answer is, "what rock am I standing on, and where and when did it form?" Finding the answer to such a question previously required either knowledge and direct observation of the rock record or finding a scaleappropriate geological map and estimating a location on that map relative to landmarks or a GPS device's coordinates, which could require conversion to the coordinate system used on the map. Then, once a geological age and context was acquired from a map or other published source, a user would still typically have to locate and consult other sources for a reconstructed paleogeographic position at the time that the rock formed.

Macrostrat's data infrastructure allows users to answer the "what am I standing on" question in real time anywhere in the world, with levels of detail that vary regionally. For example:

$$
\begin{gathered}
\text { https: //macrostrat .org/api/v2/geologic_units/ } \\
\text { map?lat=40\&lng=-89 }
\end{gathered}
$$

This API statement, which can be automatically generated by an application running on most mobile devices, returns all geologic map-based data for the specified latitude-longitude coordinates (in World Geodetic System 1984). In the case above, Macrostrat has three different geological maps that intersect this point at different 


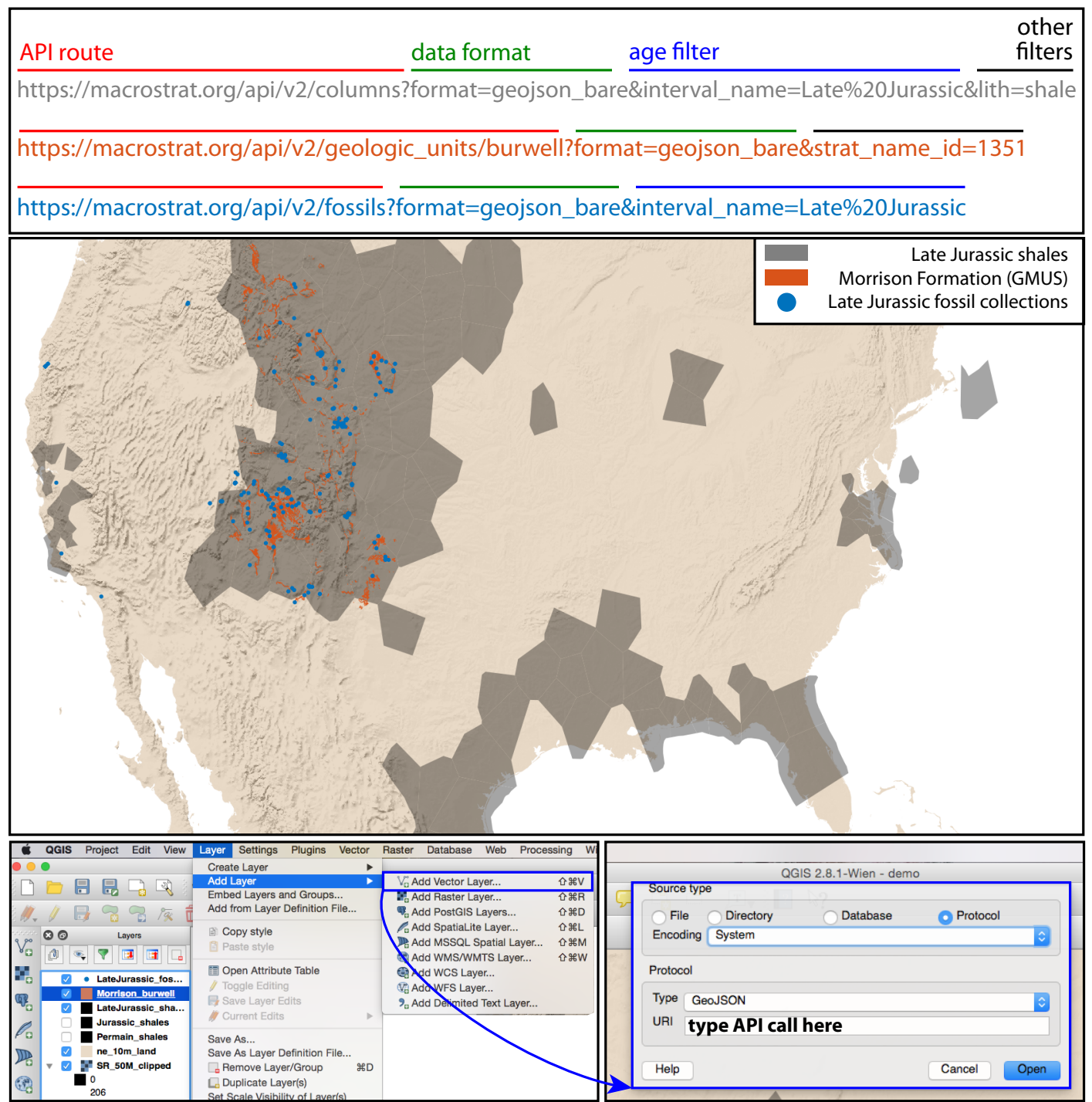

FIG. 8. Example Macrostrat API routes illustrating general URL formatting and the spatial compositing of Macrostrat data within QGIS visualization application (version 2.18).

scales. Information about the map unit from each source, along with reference information, is returned. This same data infrastructure also allows users to get elevation using digital elevation models (ETOPO1, SRTM1) instead of the elevation reported by their device's GPS chip, which is prone to large errors in vertical position (GPS- and device-specific uncertainty in horizontal position still occurs and will affect elevation estimates; precision of the GPS-supplied latitude-longitude estimate is reported in Rockd). Additionally, by retrieving data from a web API wrapper of GPlate's ${ }^{60}$ PyGPlates Python package, users are automatically given their paleogeographic position for any time going back to $750 \mathrm{Ma}$. When the age of the geological materials that the user is standing on are within this temporal window, the reconstructed position is one tap away. Global paleogeographic reconstructions and the user's paleoposition on them for all time intervals are shown on stylized maps from C.R. Scotese ${ }^{69}$. Rockd's reliance on Macrostrat's API (and it's own internal API) allows the application to be continually updated without any user intervention (e.g., a new geological map added to Macrostrat will be accessible without requiring that a user install a new version of the application).

In addition to giving local geological context to all users, Rockd allows registered users to record their own field observations and to make them public. User observations can leverage existing geological knowledge, such as stratigraphic names, lithologies, and taxonomic names that are known to occur around the observer's location. Providing this type of location-specific information to users in advance of their data acquisition can speed up the process and improve the quality of data by reducing the need for typing entries. Delivering local geological context also encourages users, at least in principle, to focus their efforts on making observations that supply new information or that complements or revises existing information, thereby enhancing local geological knowledge and improving the completeness of unit descriptions. All Rockd photos, observations and locations acquire distinct persistent URLs that, when made public by user choice, can be shared (e.g., https://rockd.org/checkin/1727) and commented on by other registered Rockd users. Thus, 

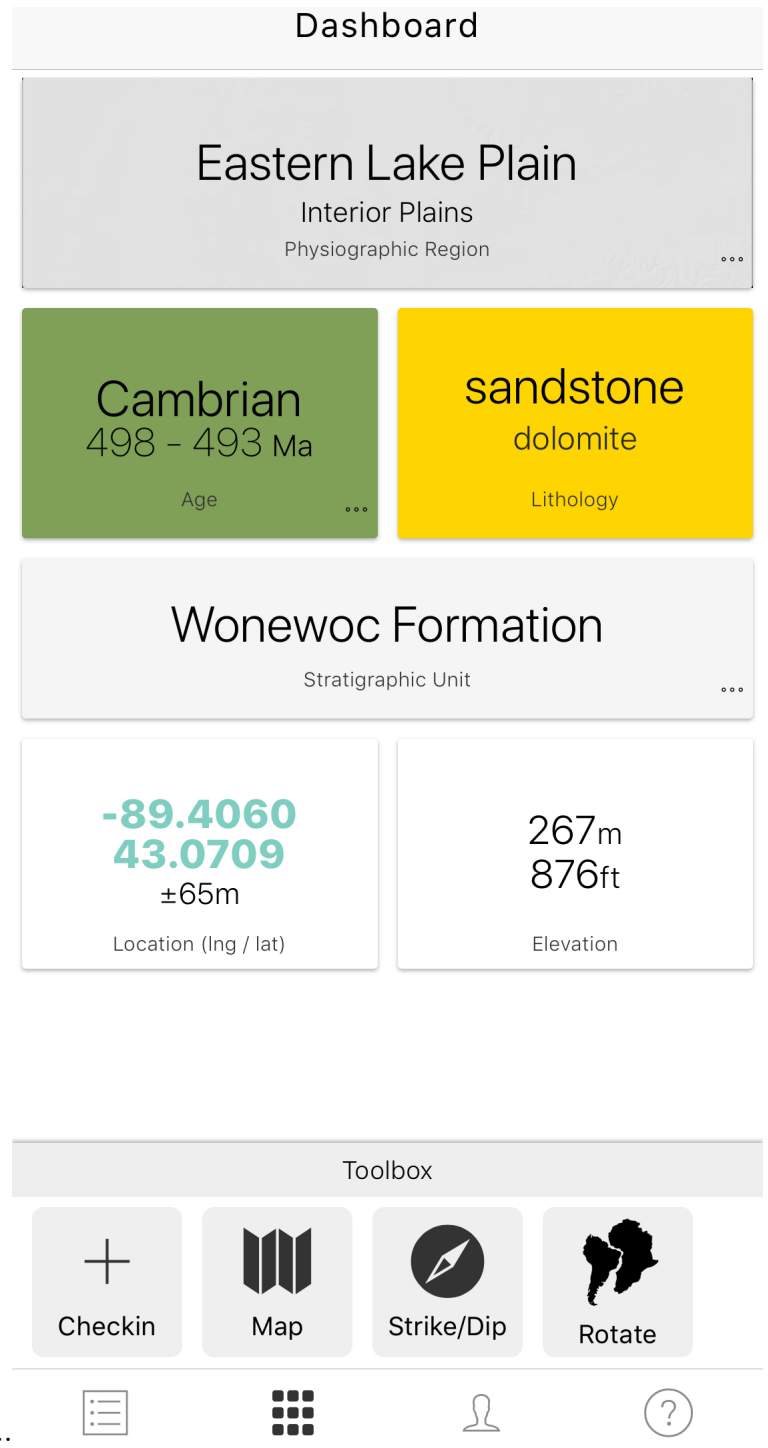

FIG. 9. Dashboard application view in the mobile application Rockd (version 2.3.2). Location-based queries are automatically generated by the App and relevant local geological data are displayed to the user. No interaction after App launch is required to obtain this estimate. Logged-in users can contribute field observations and tag geological units, thereby potentially enhancing Macrostrat with on-site data.

the app offers a vehicle to label locations with alternative interpretations or suggest modifications to the data.

As a crowd-sourced geospatial database focused on geologically-relevant locations, most of which are associated with one or more photographs, Rockd data can be useful when exploring local geology. User-contributed checkins (Rockd's term for a location with one or more observations) can also help streamline field work and the planning of field trips. The ability to create custom, ordered groupings of locations that can be named and identified by a single URL is forthcoming and will serve as the organized "field trip" component of Rockd.

Rockd has its own GIS database to store and distribute user-contributed data, but the Macrostrat API makes the application entirely functional in read-only mode to any user, including unregistered users. Basic geological data, from more than 2.1 million bedrock polygons from 170 geological maps from around the world, tens of thousands of lithostratigraphic names, most with hierarchy and ages, lists of known lithologies, minerals, and more are all supplied by the Macrostrat API. Many different types of geological applications serving many different purposes can therefore be constructed from or augmented with Macrostrat data. All such applications would acquire the ability to be continuously updated automatically as the database expands and improves.

\section{SUPPORT AND LICENSING}

The data and functionality currently offered by Macrostrat were compiled and built by Peters and a small team working with him since approximately 2006 . Grants focused on scientific questions from the National Science Foundation, the American Chemical Society, and the USGS supported initial data compilation and analysis during the period from 2006 through approximately 2010. New data and functionality powering third-party applications and the API have come online since 2013 and continue to be expanded and improved, thanks primarily to support from an NSF CAREER award and grants from the NSF EarthCube initiative, both of which have objectives that include the building of data infrastructure components.

All Macrostrat data are provided "as-is" and licensed under a Creative Commons Attribution 4.0 International license (CC BY 4.0), which requires attribution (complete attribution includes the database as well as original references associated with the data used). Individuals and teams making use of Macrostrat data or tools are encouraged to contact Macrostrat team members and seek active collaborations, which may help to enhance or customize access to data, contribute to hypothesis testing and development, and motivate additional improvements to the Macrostrat platform.

\section{EXAMPLE RESULTS AND FUTURE DIRECTIONS}

As discussed at the outset, the primary scientific motivation for building and continuing to improve Macrostrat is testing fundamental hypotheses about rock preservation and cycling ${ }^{32,54}$ and the drivers of biological $^{33,41,70-72}$ and biogeochemical ${ }^{14,16}$ evolution. Recent implementation of the preliminary continuoustime age model (Fig. 3) has enabled us to conduct substantive quantitative analyses of the Precambrian sedimentary rock record and to compare that record to the Phanerozoic. Shifting to a time interval-free approach to measuring rock quantity was important because the much longer subdivisions of Precambrian time impart a strong signal when conducting interval-based analyses ${ }^{44}$. The longest-term history of sediment quantity in the area covered by Macrostrat (Fig. 2) is remarkable in several different ways (Fig. 10). Most notably, the step-wise increase in sediment quantity across the Precambrian-Cambrian boundary marks what has 


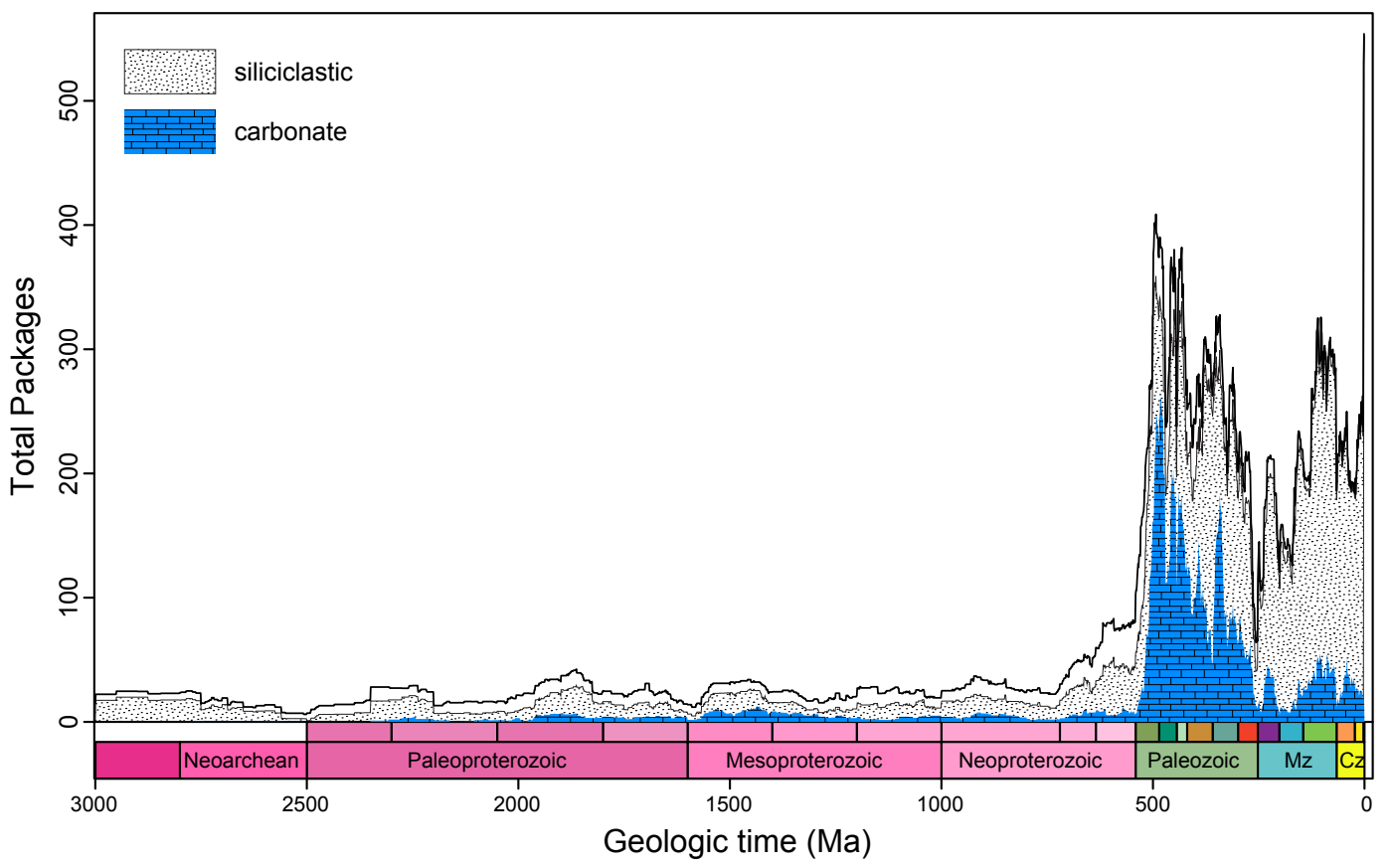

FIG. 10. Total number of sedimentary (including metasedimentary) rock packages in North America (Fig. 1; a total of 1,013 columns are present in this area). Lithologies are subivided into three groups: carbonates, siliciclastics, and all others (no color or fill). Units with multiple lithologies are weighted according to the proportion of each group (e.g., a package with a unit composed of $50 \%$ carbonate and $50 \%$ sandstone would contribute 0.5 package units to each lithology type).

been called the "Great Unconformity"72,73. Determining whether this strong signal of increased sediment quantity on the continents is North America-specific or a global phenomenon is critical to addressing many fundamental questions about the evolution of Earth and life ${ }^{16}$.

A current major limitation of Macrostrat is the geographically restricted nature of its surface-subsurface data (i.e., columns). Currently, Macrostrat columns cover approximately $15 \%$ of the global continental crust, most of which is in North America (Fig. 2). Although evidence suggests that there is indeed a global expression of the Great Unconformity ${ }^{16,74}$, testing this hypothesis requires geographic expansion of column coverage. We hope that this objective will be facilitated by engaging geoscientists with regional expertise and leveraging their in-hand knowledge. Because the units comprising each column in Macrostrat can, at least initially, comprise only the most basic information on lithology, age, and thickness of geological units, many regional geoscientists now have the necessary knowledge and data in-hand. The accuracy and precision of the general summaries can be improved once the scaffolding that completely describes the upper crust is in place.

To facilitate the task of geographic expansion, some of the basic data required for column entry has already been incorporated into Macrostrat. For example, Australia is represented by geological map data at multiple scales and by the entire Australian stratigraphic lexicon. These data, in combination with definitions of lithology, lithology attributes, and chronostratigraphic intervals, mean that the process of entering a new column in Australia would require: 1) defining the geographic region of interest by designating a bounding geometry, 2) defining a chronostratigraphic succession of units that are linked to lithologies, thicknesses and, optionally, lithostratigraphic names and environments of formation. In order to obtain the highest-quality initial columns, participation of regional experts is the ideal path forward. Launching a globally-comprehensive initiative to harness regional geological expertise and synthesize it in Macrostrat would have many far-reaching, positive impacts, including enabling key hypotheses to be tested and establishing a digitally-accessible, comprehensive working model of the age and material properties of rocks in the Earth's upper crust.

\section{ACKNOWLEDGMENTS}

Macrostrat database and infrastructure development supported principally by US National Science Foundation EAR-1150082 and ICER-1440312. GeoDeepDive infrastructure development supported by NSF ICER 1343760. We thank Matthew Kosnik, Fred Ziegler, Bruce Wilkinson, Michael Foote, Alan Carroll, Steve Meyers, Michael McClennen, Steve Holland, and Andrew Zaffos for their input and feedback on the approach of macrostratigraphy and on database development. Noel Heim, Deborah Rook, Sharon McMullen, Neal Auchter, Annaka Clement, and Jarrett Smith aided in data entry and editing. Noel Heim and Puneet Kishor provided invaluable contributions to the database and initial efforts to integrate geological maps. We also thank the Paleobiology Database contributors, whose combined efforts have resulted in a rich fossil data resource. This is Paleobiology Database Official Publication NUM. 


\section{References}

${ }^{1}$ A. Ronov, V. Khain, A. Balukhovsky, and K. Seslavinsky, Sedimentary Geology 25, 311 (1980).

${ }^{2}$ R. A. Berner, Global and Planetary Change 1, 97 (1989).

${ }^{3}$ W. W. Hay and M. A. Leslie, Sea-Level Change, 161 (1990).

${ }^{4}$ T. Gleeson, K. M. Befus, S. Jasechko, E. Luijendijk, and M. B. Cardenas, Nature Geoscience 9, 161 (2015).

${ }^{5}$ B. H. Wilkinson and J. C. Walker, American Journal of Science 289, 525 (1989).

${ }^{6}$ C. N. Wold and W. W. Hay, American Journal of Science 290, 1069 (1990).

${ }^{7}$ B. H. Wilkinson, B. J. McElroy, S. E. Kesler, S. E. Peters, and E. D. Rothman, Geological Society of America Bulletin 121, 760 (2009).

${ }^{8}$ D. J. Gombosi and B. H. Wilkinson, The Journal of Geology 120, 121 (2012).

${ }^{9}$ M. I. Budyko, A. B. Ronov, and A. L. Yanshin, History of the Earth's atmosphere. (Springer-Verlag, 1987).

${ }^{10}$ R. A. Berner and D. E. Canfield, Am. J. Sci 289, 333 (1989).

${ }^{11}$ D. Des Marais, H. Strauss, R. Summons, and J. Hayes, Nature 359 (1992).

${ }^{12}$ R. A. Berner and Z. Kothavala, American Journal of Science 301, $182(2001)$

${ }^{13}$ N. M. Bergman, T. M. Lenton, and A. J. Watson, American Journal of Science 304, 397 (2004).

${ }^{14}$ I. Halevy, S. E. Peters, and W. W. Fischer, Science 337, 331 (2012).

${ }^{15}$ D. P. Schrag, J. A. Higgins, F. A. Macdonald, and D. T. Johnston, Science 339, 540 (2013).

${ }^{16}$ J. M. Husson and S. E. Peters, Earth and Planetary Science Letters 460, 68 (2017).

${ }^{17}$ T. Gleeson, K. M. Befus, S. Jasechko, E. Luijendijk, and M. B. Cardenas, Nature Geoscience 9, 161 (2016).

${ }^{18}$ Y. Fan, S. Richard, R. Bristol, S. E. Peters, S. E. Ingebritsen, N. Moosdorf, A. Packman, T. Gleeson, I. Zaslavsky, S. Peckham, et al., Crustal Permeability , 6 (2016).

${ }^{19}$ W. D. Mooney, G. Laske, and T. G. Masters, Journal of Geophysical Research: Solid Earth 103, 727 (1998).

${ }^{20}$ D. M. Raup, Paleobiology 2, 289 (1976).

${ }^{21}$ J. J. Sepkoski, Paleobiology 2, 298 (1976).

${ }^{22}$ S. E. Peters and M. Foote, Paleobiology 27, 583 (2001).

${ }^{23}$ A. B. Smith, Philosophical Transactions of the Royal Society of London B: Biological Sciences 356, 351 (2001).

${ }^{24}$ M. J. Benton, P. C. Donoghue, R. J. Asher, M. Friedman, T. J. Near, and J. Vinther, Palaeontologia Electronica 18, 1 (2015).

${ }^{25}$ S. E. Peters and N. A. Heim, Paleobiology 36, 61 (2010).

${ }^{26}$ J. Alroy, C. Marshall, R. Bambach, K. Bezusko, M. Foote, F. Fürsich, T. A. Hansen, S. Holland, L. Ivany, D. Jablonski, et al., Proceedings of the National Academy of Sciences 98, 6261 (2001).

${ }^{27}$ J. Alroy, M. Aberhan, D. J. Bottjer, M. Foote, F. T. Fürsich, P. J. Harries, A. J. Hendy, S. M. Holland, L. C. Ivany, W. Kiessling, et al., Science 321, 97 (2008).

${ }^{28}$ J. Alroy, Science 329, 1191 (2010).

${ }^{29}$ S. E. Peters and M. McClennen, Paleobiology 42, 1 (2016)

${ }^{30}$ S. E. Peters, C. Zhang, M. Livny, and C. Ré, PLoS ONE 9, e113523 (2014)

${ }^{31}$ S. E. Peters, J. M. Husson, and J. Wilcots, Geology 45, 487 (2017).

${ }^{32}$ S. E. Peters, The Journal of Geology 114, 391 (2006).

${ }^{33}$ S. E. Peters (2008) pp. 205-232.

${ }^{34}$ B. Hannisdal and S. E. Peters, The Journal of Geology 118, 111 (2010).

${ }^{35}$ W. Aswasereelert, S. Meyers, A. Carroll, S. Peters, M. Smith, and K. Feigl, Geological Society of America Bulletin 125, 216 (2013).

${ }^{36}$ P. R. King, T. R. Naish, G. H. Browne, B. D. Field, and S. W. Edbrooke, Cretaceous to Recent Sedimentation in New Zealand, Folio Series, Vol. 1 (Institute of Geological \& Nuclear Sciences Limited, 1999)

${ }^{37}$ O. E. Childs, AAPG Bulletin 69, 173 (1985).

${ }^{38}$ F. Maurrasse, Dengo, G., and Case, JE, edits., Decade of North American Geology, Volume H: The Caribbean Region, Boulder, Colo., Geol. Soc. America Inc., Plate 4 (1990).
${ }^{39}$ D. Stott, Sedimentary cover of the craton in Canada, Geological Society of America, Geology of North America, D-1, sheet 1 (1991).

${ }^{40}$ H. Trettin, "Geology of canada," (Geological Survey of Canada, 1991) Chap. Geotectonic correlation chart.

${ }^{41}$ S. E. Peters, D. C. Kelly, and A. J. Fraass, Nature 493, 398 (2013).

42 A. J. Fraass, D. C. Kelly, and S. E. Peters, Annual Review of Earth and Planetary Sciences 43, 139 (2015)

${ }^{43}$ F. M. Gradstein, G. Ogg, and M. Schmitz, The Geologic Time Scale 2012 (Elsevier, 2012).

${ }^{44}$ P. M. Sadler, The Journal of Geology 89, 569 (1981).

${ }^{45}$ S. R. Meyers, S. E. Siewert, B. S. Singer, B. B. Sageman, D. J. Condon, J. D. Obradovich, B. R. Jicha, and D. A. Sawyer, Geology 40, 7 (2012)

${ }^{46}$ USGS, "National geologic map database," (2016).

${ }^{47}$ GSC, "Generalized geological map of the world and linked databases," Open File Report 2915d (Geological Survey of Canada, 1995)

${ }^{48}$ C. P. Garrity and D. R. Soller, "Database of the geologic map of north america; adapted from the map by j.c. reed, jr. and others (2005)," http://pubs.usgs.gov/ds/424/ (2009).

${ }^{49}$ S. Ludington, B. C. Moring, R. J. Miller, P. A. Stone, A. A. Bookstrom, D. R. Bedford, J. G. Evans, G. A. Haxel, C. J. Nutt, K. S. Flyn, and M. J. Hopkins, USGS Open-File Report 20051305 (2005).

${ }^{50}$ C. Garrity and D. Soller, "Database of the Geologic Map of North America; adapted from the map by J.C. Reed, Jr. and others (2005)," Data Series 424 (U.S. Geological Survey, 2009).

${ }^{51}$ O. Raymond, S. Liu, R. Gallagher, L. Highet, and W. Zhang, "Surface geology of Australia, 1:1 000000 scale, 2012 edition [digital dataset]," Tech. Rep. (Geoscience Australia, Commonwealth of Australia, Canberra, 2012).

52 A. B. Smith and A. J. McGowan, Palaeontology 50, 765 (2007).

${ }^{53}$ P. D. Wall, L. C. Ivany, and B. H. Wilkinson, Paleobiology 35 , 146 (2009).

${ }^{54}$ S. E. Peters and J. M. Husson, Geology 45, 323 (2017).

${ }^{55}$ L. Brand, M. Wang, and A. Chadwick, Scientific data 2 (2015).

${ }^{56} \mathrm{C}$. Amante and B. W. Eakins, ETOPO1 1 arc-minute global relief model: procedures, data sources and analysis (US Department of Commerce, National Oceanic and Atmospheric Administration, National Environmental Satellite, Data, and Information Service, National Geophysical Data Center, Marine Geology and Geophysics Division Colorado, 2009).

${ }^{57}$ T. G. Farr, P. A. Rosen, E. Caro, R. Crippen, R. Duren, S. Hensley, M. Kobrick, M. Paller, E. Rodriguez, L. Roth, et al., Reviews of Geophysics 45 (2007).

${ }^{58}$ J. Valentine and E. Moores, Nature 228, 657 (1970).

${ }^{59}$ A. Zaffos, S. Finnegan, and S. E. Peters, Proceedings of the National Academy of Sciences 114, 5653 (2017).

${ }^{60}$ N. Wright, S. Zahirovic, R. D. Müller, and M. Seton, Biogeosciences 10, 1529 (2013).

${ }^{61}$ W. Cao, S. Zahirovic, N. Flament, S. Williams, J. Golonka, and R. D. Müller, Biogeosciences 14, 5425 (2017).

${ }^{62}$ S. E. Williams, R. D. Müller, T. C. Landgrebe, and J. M. Whittaker, GSA Today 22, 4 (2012).

${ }^{63}$ A. S. Merdith, A. S. Collins, S. E. Williams, S. Pisarevsky, J. F. Foden, D. Archibald, M. L. Blades, B. L. Alessio, S. Armistead, D. Plavsa, et al., Gondwana Research (2017).

${ }^{64}$ M. Seton, R. Müller, S. Zahirovic, C. Gaina, T. Torsvik, G. Shephard, A. Talsma, M. Gurnis, M. Turner, S. Maus, et al., EarthScience Reviews 113, 212 (2012).

${ }^{65}$ K. J. Matthews, K. T. Maloney, S. Zahirovic, S. E. Williams, M. Seton, and R. D. Müller, Global and Planetary Change 146, 226 (2016).

${ }^{66}$ R. D. Müller, M. Seton, S. Zahirovic, S. E. Williams, K. J. Matthews, N. M. Wright, G. E. Shephard, K. T. Maloney, N. Barnett-Moore, M. Hosseinpour, et al., Annual Review of Earth and Planetary Sciences 44, 107 (2016).

${ }^{67}$ R. T. Fielding, Architectural Styles and the Design of Networkbased Software Architectures, Ph.D. thesis, University of California, Irvine, California (2000).

${ }^{68}$ M. P. Nelsen, W. A. DiMichele, S. E. Peters, and C. K. Boyce, Proceedings of the National Academy of Sciences 113, 2442 
(2016).

${ }^{69}$ C. Scotese, "Paleomap paleoatlas for gplates and the paleodata plotter program," http://www.earthbyte.org/ paleomap-paleoatlas-for-gplates/ (2016).

${ }^{70}$ S. E. Peters, Nature 454, 626 (2008).

${ }^{71}$ B. Hannisdal and S. E. Peters, Science 334, 1121 (2011).

${ }^{72}$ S. E. Peters and R. R. Gaines, Nature 484, 363 (2012).

${ }^{73}$ K. E. Karlstrom and J. M. Timmons, Geological Society of Amer- ica Special Papers 489, 73 (2012).

${ }^{74}$ T. He, Y. Zhou, P. Vermeesch, M. Rittner, L. Miao, M. Zhu, A. Carter, P. A. P. von Strandmann, and G. A. Shields, Geological Society, London, Special Publications 448, 145 (2017).

${ }^{75}$ S. R. Meyers and S. E. Peters, Earth and Planetary Science Letters 303, 174 (2011). 